\title{
Dos indicadores sociais aos analisadores sociais
}

René Lourau

Capítulo VII (Des indicateurs sociaux aux analyseurs sociaux) do livro L'État-inconscient. Paris: Les Éditions de Minuit, 1978, p. 125 a 138.

Tradução: Solange L'Abbate. Revisão: Yvone Greis

Notas do trabalho de tradução - As aspas, itálico e palavras no meio do texto iniciadas com letra maiúscula foram mantidos como aparecem no texto original. Há apenas uma nota de rodapé do texto original, que está indicada; as demais foram acrescentadas no decorrer do trabalho de tradução. Ao final, encontra-se uma relação dos autores citados no texto, que foi organizada por doutorandos em Saúde Coletiva da Faculdade de Ciências Médicas da Universidade Estadual de Campinas: Daniel Vannucci Dóbies; Ana Cristina dos Santos Vangrelino; Juliana Dorigan Hespanhol; Lia Bissoli Malaman e Tatiana Loiola.

DOI: 10.12957/mnemosine.2020.52693

Desde os anos 60, os economistas e os políticos encontraram uma base que se quer científica para o discurso do poder: os indicadores sociais, ou informações quantificadas relativas à maior parte dos problemas, ou extensão do tratamento estatístico para todos os aspectos da vida.

Como qualquer novo conhecimento, este conceito vê sua gênese teórica estreitamente determinada por sua gênese social: neste caso, a grande crise de 1929. Os especialistas americanos atuais associam o uso regular dos indicadores à chegada de Roosevelt ao poder e, portanto, à nova linha econômico-política conhecida pelo nome de New Deall, a "nova estratégia". Com Roosevelt, as Mensagens sobre o estado da União contêm indicadores quantificados em número crescente. Estes indicadores não se referem apenas à economia, mas também aos problemas sociais.

$\mathrm{Na}$ França, foi preciso esperar a chegada da direita modernista ao governo para que o método dos indicadores sociais viesse enriquecer o arcabouço teórico dos planejadores. O período ao qual se faz alusão é aquele do ministério de Chaban-Delmas, na primeira parte do governo Pompidou.

A reflexão sobre o planejamento e a difusão da ideologia planificadora conheceram um nítido progresso alguns anos antes da chegada dos modernistas ao poder. Além de algumas reflexões individuais ou das garantias de uma marca individual 
como Playdoyer pour l'avenir de Louis Armand, La République moderne de Pierre Mendès-France (modernista de esquerda rapidamente afastado do poder na IV $^{\text {a }}$ República), Le Plan ou l'anti-hasard de Pierre Massé, a publicação que faz ressoar os primeiros compassos da quinta sinfonia dos planejadores é a obra coletiva das equipes de preparação do Vº Plano, Réflexions pour 1985.

Estas reflexões, tornadas públicas em 1964, são o fruto de um trabalho iniciado em 1962, ao final da guerra da Argélia, pelo "grupo 1985", como ele mesmo se designava.

Reflexões para 1985 contém em anexo uma série de tabelas prospectivas, baseada na técnica da extrapolação por um período de vinte anos. Estas extrapolações, a partir das estatísticas do I.N.S.E.E ${ }^{2}$. (dezembro 62), referem-se a alguns grandes capítulos apreciados pelos planejadores: produtividade, crescimento, consumo doméstico, níveis de qualificação, evolução do parque automotivo, moradias a serem construídas e...evolução dos ativos empregados. As previsões que compreendem o período 1964-1985 são imaginadas em função da metafísica do crescimento. Os planejadores esquecem alguns detalhes: a história, as contradições na evolução das forças e das formas sociais em escala mundial. Por exemplo, este acontecimento, fantástico por não ter sido previsto pelos especialistas da prospectiva, que não é outra coisa senão a inflação, a onda de desemprego e o álibi mágico do argumento do preço do petróleo pelos países que o produzem e o vendem aos países capitalistas mais poderosos. Veremos que é precisamente partindo deste tipo de esquecimento dos planejadores e, em geral, dos especialistas em matéria de análise e de previsão que a teoria dos indicadores sociais deverá ser substituída por outra teoria.

Fim de 67, início de 68: Jacques Delors, encarregado de pensar o "social" nas equipes do Plano, difunde a teoria dos indicadores sociais na Escola Nacional de administração. No mesmo momento, em Nanterre e em alguns outros lugares, começa o trabalho dos analisadores sociais, que ia desembocar na análise institucional generalizada de maio-junho de 68. As duas tarefas não existem sem relação, como mostra a própria carreira de Delors. Embora a brecha de 68 tenha sido rapidamente preenchida pelo poder, este último vacila menos de um ano depois dos acontecimentos de maio-junho. Em 1969, o referendo sobre a regionalização, do qual o general de Gaulle não ocultou o caráter de plebiscito, trouxe um resultado negativo. De Gaulle sai, Pompidou chega e, com ele, Chaban-Delmas assume o posto de Primeiro ministro. É chegada a vez de Jacques Delors. 
Como conselheiro do Primeiro ministro, ele vai peneirar para o uso de seu chefe temas da "sociedade bloqueada", caros ao sociólogo modernista Michel Crozier (cujo livro é publicado em 1970), e introduzir no cálculo político a teoria dos indicadores. O I.N.S.E.E., o Tribunal de contas, a Contabilidade nacional são definitivamente entronizados como deusas-mães da arte política. Ministério brilhante, reformista de direita inteligente: os conservadores acabarão por não mais suportar este desafio aos seus métodos comprovados, e o novo presidente da República exonerará brutalmente Chaban-Delmas, apoiado, entretanto, pela confiança da maioria parlamentar.

Alguns anos mais tarde, Jacques Delors passa do reformismo de direita ao reformismo de esquerda. Quase ao mesmo tempo que seu colega ex-esquerdista Rocard, ele entra no partido socialista, com seus indicadores discretamente armazenados no fundo de sua pasta. O modernismo chabanista era, de longe, o gaullismo menos ruim. Mas, é, naturalmente, o pior socialismo. Pobre Delors. Pobre Rocard. Pobre Attali. Pobres economistas promovidos ao lugar de conselheiros dos grandes deste mundo, e isso quando eles mesmos não são chamados aos postos de direção política: de Turgot a Salazar e de Milton Friedman a Raymond Barre, a lista destes especialistas em ciência política ou econômica começa a ficar longa, arrancados da tranquilidade de sua existência intelectual. São no fundo os "indicadores" (no sentido de agentes de informação) que a Ciência delega ao Poder para ser validada.

Delors apresenta em 1971, com Les indicateurs sociaux (Éditions Futuribles), uma tese sustentada menos em sólidos materiais do que na inspiração otimista de um professor Nimbus ${ }^{3}$ em plena “Eureka!”. Nela se encontra uma exposição clara, ainda que sucinta, da teoria dos indicadores.

Com efeito, este conceito existe desde há muito tempo nas ciências sociais, seja na sociologia ou na economia. Mas, ao generalizar seu emprego no domínio político, ele se insere consequentemente numa teoria nova, a teoria das mudanças sociais identificadas financeiramente: "Trata-se (...) de evidenciar as escolhas explícitas, mas também frequentemente implícitas, feitas pela coletividade ou pelos indivíduos sem medir todas as consequências das decisões que são assim tomadas. "Exprimir através de dados quantificados o estado de uma nação, tal é o objetivo. Ou ainda, como diz William Gorham, teórico americano dos indicadores sociais, "fornecer indicadores razoáveis, ainda que aproximados, da amplitude dos problemas socioeconômicos e da extensão dos progressos realizados no tratamento destes problemas" (Gorham, 1967, citado por Delors). 
O problema é encontrar dados quantificados para uma multiplicidade de indicadores referidos a grande número de temas. Dentre os vinte e um temas selecionados por Delors, citemos a esperança de vida, o comportamento no que diz respeito aos marginalizados, a utilização do tempo... "O que se esperava era que todos os temas escolhidos traduzissem finalidades do desenvolvimento, uma vez que tal é certamente o objetivo fundamental desta pesquisa. Os indicadores teriam exprimido objetivos e meios em conformidade com estes objetivos". Mas tal abordagem é prematura. Pois, o problema das finalidades é dificilmente quantificável. Ao fazer a distinção entre "indicadores de resultados" e "indicadores de meios", Delors pensa, no entanto, na utilização eventual dos indicadores sociais "no estabelecimento dos planos, que devem se basear numa associação íntima dos objetivos e dos meios".

A quantificação da maior parte dos indicadores, ao final de cada curto capítulo consagrado aos diversos temas, torna-se extremamente resumida. Os indicadores indicam pouca coisa, ou nada. Por exemplo, sob o tema "A organização do espaço rural", o indicador n 13 , "Indicador da poluição das águas", não existe a não ser como projeto, devido “à complexidade dos fenômenos"...

Em resumo, e com a condição de que os progressos alcançados tenham permitido uma verdadeira utilização dos indicadores no planejamento destes últimos anos (seria necessário verificar), a "teoria explicativa da mudança social", com a qual sonham, conforme Delors, tanto os sociólogos quanto os "centros de decisão", não está pronta para sair deste voluntarismo da quantificação.

A quantificação não é questionada diretamente, mas somente enquanto ela é emancipada pelos planejadores ávidos de indicadores. Opor o quantitativo ao qualitativo procede de uma abordagem estéril, visto que os quantificadores reconhecem, cedo ou tarde, que o que organiza a matéria quantificável, as "finalidades", é do domínio do qualitativo, e que os fanáticos do qualitativo são obrigados cotidianamente a mensurar, ainda que isso represente os seus meios de sobrevivência. Se se considera o projeto global, a ambição de um Cálculo total e totalitário como reforço ou mesmo, no limite, substituto dos procedimentos habituais da política instituída, então são os interesses, as finalidades e o próprio jogo desta política instituída que devem ser questionados.

O planejamento absoluto, é sabido, nasceu por e para a economia da guerra total. Desde os modestos planejamentos de Monnet, na França, e de Rathenau, na Alemanha, durante a Primeira Guerra mundial, até a religião planificadora atual ("a ardente obrigação" proclamada por de Gaulle enquanto a grande questão da guerra da 
Argélia acabava de desaparecer), passando pela violência à maneira de Átila do Gosplan soviético ${ }^{4}$, pelas revisões nefastas do $\mathrm{New}$ Deal, pelos devaneios antecipatórios dos primeiros planejadores franceses e dos gigantescos trabalhos práticos de Speer na Alemanha nazista, a obrigação planificadora é tanto mais ardente quanto o fogo das armas se faz mais destruidor das máquinas de produção concorrentes. A crise, desde 1929, permite manter, em tempo de paz, a ideologia de emergência, o pequeno apocalipse quantificado do qual as publicações do M.T.I ${ }^{5}$ fornecem um exemplo. Entre a crise e a guerra, as relações se fazem mais e mais funcionais, seja na realidade ou no imaginário. Reforçando-se mutuamente, a crise real e a guerra possível (ou a guerra real e a crise possível) são as duas fadas que se inclinam sobre a teoria planificadora. É, portanto, a aceitação deste jogo que determina, no nível mais elevado, o projeto de racionalidade planificadora. Jogo planetário do capital que somente a sua destruição permitirá desfazer.

A concorrência e o desequilíbrio mundiais são elementos essenciais que justificam a persistência da política instituída, da sacralização da forma "Estado" e da luta cada vez mais atroz que rege as relações entre estas formas supremas nas quais se materializam, aproximadamente, cento e quarenta fragmentos extremamente desiguais da humanidade. O desprezo infinito (o desapreço ${ }^{6}$ exigido pela mercadoria), que caracteriza as relações entre os Estados, contradiz absolutamente a valorização do Estado no interior de cada forma estatal. Isto dá uma ideia do avanço das contradições que levam historicamente ao enfraquecimento e à extinção do Estado. Este mesmo processo atinge necessariamente também a ideia de centro - centro de decisão, lugar do poder para a política instituída em todos os fragmentos da humanidade, reconhecidos como Estados pela O.N.U. Ora, a ideia de plano, como isto é chamado de passagem e quase de forma negligente pela profecia dos indicadores sociais, é inseparável da ideia de "centro de decisão", exigido no sistema atual não somente pelo reforço da máquina militar estatal, mas pela luta contra "a anarquia" do liberalismo econômico.

A luta contra a política instituída passa pela luta contra o conceito de centro e contra qualquer centralidade. O planejamento é o último avatar da religião da centralidade. O fascismo, o nazismo, o stalinismo e algumas outras formas de dominação modernas são variações litúrgicas (históricas, culturais). Variações que têm uma significação essencial em relação à produção de representações pela política instituída - em relação à curvatura do campo social pelo político. 
A centralidade é o lugar da dominação que se dissimula atrás dos aspectos funcionais da regulação indispensável em qualquer escala do território. Ela não pode preencher este papel senão fabricando o valor supremo que é a representação: o centro não existe a não ser pela ausência que lhe delega qualquer poder. Quanto maior for esta delegação, mais presente é o centro na periferia.

O poder é representação, teatro, simulacro e não vive senão pelos espectadores "que participam" da ação, diante da sua televisão, no dia das eleições e todos os dias, todas as noites, no seu Estado-inconsciente. Se a psicanálise colocar letra maiúscula nos Estados inconscientes, a ciência política poderá fazer enormes progressos! Porque o Estado é o inconsciente, ou antes, porque o inconsciente é o Estado - o sonhado império austro-húngaro em plena "dissolução da transferência" dos povos com respeito aos Habsburgos ${ }^{7}$, durante a "resistência" em relação à instituição estatal e sua paranoia da indivisibilidade.

Como a representação é o terreno ideal da lei do valor (tal coisa "representa" um valor de $n$ ), ela condensa todo o qualitativo esvaziado pelo sistema do Cálculo totalitário. Mas, trata-se de um qualitativo corroído pelo quantitativo. Como o valor, a representatividade é uma taxa, um índice quantificável. É possível ser mais ou menos representativo em função do número de ausentes que se demitem ou que são vampirizados em nome da delegação de poder e do mandato. As pesquisas, pela concorrência que elas fazem com os órgãos representativos eleitos ou nomeados, indicam também o reino do quantitativo atrás da qualidade pura da representação. Não há, mesmo no discurso político, quem revele, pelo tom religioso ou militar dos profissionais, portanto pela referência implícita dos grandes modelos institucionais do exército e da Igreja, a inexistência de uma qualidade própria do político: este último tem necessidade de uma qualidade emprestada, porque o conteúdo do conceito de representação escapa sem cessar para o quantitativo puro, para a contabilidade eleitoral, ou para "os grandes batalhões", fontes reais do poder.

O princípio de equivalência que rege a mercadoria, graças ao "equivalente geral" que é a moeda, rege, da mesma forma, a representação. A extrema flexibilidade, a circularidade da ideologia manipulada pelos profissionais da política ou por seus experts, permitem que a política seja instituída como um jogo com seu campo, seus interesses, suas regras - e, consequentemente, com seus impedimentos, seu poder de recuperação de novos interesses, suas transgressões. 
Estes três reflexos bizarros da política instituída não são aplicados facilmente ao planejamento? Por muito tempo longe do jogo político, assunto de grandes cabeças um pouco racionalistas demais; propondo uma questão concorrente com aquela que a política tradicional se determinava, a saber, a conservação ou a conquista do Estado - de onde resulta a aporia de Lenin ao desejar fazer do Plano a superinstituição supra estatal - mas, evidentemente, é o Estado que saiu reforçado deste confronto, porque o pensamento planificador é totalmente comandado pelo estatal; também suas transgressões, do mesmo modo que as recentes mini transgressões da corrente ecológica, servem para valorizar as regras do jogo. Conservadora ou modernista, liberal ou planificadora, a política instituída é inicialmente a liturgia de uma forma sagrada: o Estado.

O método dos indicadores sociais invadiu doravante tanto o discurso político de esquerda como o de direita. Os líderes da oposição, em seus duelos com os da maioria, rivalizam dados quantificados em apoio ao seu programa. Os números, dóceis, fazem reluzir as botas das ideologias concorrentes, e a vitória fica com aquele que, tal como Zorro, atira mais rapidamente do que o adversário, obrigando-o a confessar que tal parte de seu programa ou de sua atividade passada não se apoia sobre indicadores sérios. Viuse mesmo o partido comunista intervir na batalha política geral e na disputa interna para a união da esquerda, publicando avalanches de dados relacionados ao custo da aplicação eventual do Programa comum. Modo divertido para o partido, que dispõe potencialmente da base ideológica mais rica, de calar a boca do avô Karl em favor dos jovenzinhos tecnocratas para quem o livro I do Capital é, sem dúvida, mais uma narrativa poética do que um romance de Júlio Verne.

Contudo, as críticas internas à teoria dos indicadores não faltam. Os teóricos americanos, Biderman, Gross etc, levantam numerosos obstáculos técnicos (traduzindo: políticos, tem-se aí um lapsus corrente entre os cientistas). Estes obstáculos impedem a elaboração dos indicadores. Eles são chamados: "inadequação", "imprecisão", "conflito de indicadores", "falta de dados", "incompatibilidade de modelos estatísticos" e "ausência de consenso sobre os valores"! Estes dois últimos obstáculos são os mais graves. Eles se devem à frágil unificação dos conceitos da sociologia. Mas esta explicação não deve ser ela mesma explicada? A incompetência da sociologia na gestão do mundo é, como os sociólogos otimistas à moda de Boudon insinuam, uma simples doença da juventude (cf. La crise de la sociologie, Droz, 1971)? 
A incompatibilidade dos modelos estatísticos e a ausência de consenso sobre os valores salientados a princípio por aqueles que manipulam os dados manifestam-se em diferentes avaliações dos fenômenos sociais e em diferenças de tratamento conceitual. A estes obstáculos na elaboração acrescentam-se os obstáculos na utilização e na interpretação. Biderman observa que os indicadores mais conhecidos tendem a adquirir vida própria e a ampliarem-se, pelo uso cotidiano que deles é feito, com uma significação que não tinham originalmente. Exemplos: a criminalidade, a droga... Quanto a Gross, ele lamenta a existência de um tipo de "lei de Gresham" da informação: a má informação tende a excluir a boa, a quantitativa exclui a qualitativa - o que não acontece sem evocar as imprecações do filósofo bastante reacionário René Guénon contra "o reino da quantidade" como "sinal dos tempos", isto é, anúncio do fím do mundo.

Todas as críticas internas juntam-se às críticas externas sobre "o problema central" que é o paradoxo entre a inflação de dados e a indigência proporcionalmente crescente das perspectivas para ordená-los. Enorme obstáculo "contra o qual se chocam tanto os sociólogos, quanto aqueles que tentam guiar nossa sociedade para plena realização de suas potencialidades" (Delors, p.368)

Quando mostrei que a teoria dos indicadores sociais, no contexto mais geral do planejamento, implicava uma adesão quase religiosa às normas da política instituída (forma estatal, centralizada, flexão de todas as nossas representações, princípio de equivalência), eu não fazia senão reunir, do exterior, as críticas mais lúcidas dos teóricos aos quais se refere Jacques Delors. É tempo, em função da crítica particular que a análise institucional autoriza, de especificar a alternativa entre indicadores e analisadores.

É preciso lembrar que a teoria dos analisadores também está inacabada? Cada vez que, na prática, o conceito de analisador é validado, a teoria geral dos analisadores avança menos do que quando ela se choca contra um campo "desprovido de analisadores", isto é, na realidade, neutralizado politicamente a ponto de nos cegar sobre a existência de analisadores que não queremos ver e de uma verdade que não queremos conhecer.

O postulado sobre o qual repousa toda a teoria é que, em qualquer situação dada, a produção de analisadores sociais é a condição indispensável da percepção desta situação pelos atores ${ }^{8}$. Por exemplo, se me apresento em algum lugar para fazer uma compra ou, por qualquer outra razão, supondo uma troca mínima de palavras ou de 
serviços entre um prestador e os clientes, eu posso muito bem me retirar, uma vez a operação efetuada, sem haver percebido o mínimo funcionamento real, material e social do lugar em questão. Mas, se, durante o tempo em que faço a fila, ou durante a própria operação, ou quando estou indo embora, compreendo ou vejo um detalhe aparentemente insignificante que revela um aspecto inesperado dos bastidores do estabelecimento do qual eu sou cliente, minha percepção deixa de repente a neutralidade do "prático-inerte" (para retomar a expressão de Sartre), do instituído coisificado e sem vida, para penetrar nas relações sociais reais do estabelecimento. Esta penetração quase por arrombamento dá, em geral, apenas uma vaga ideia do que se passa, mas esta percepção é suficiente para ser analisador do que anteriormente não podia e não devia colocar problema aos olhos de um simples cliente.

A questão de encontrar o analisador, ou de cair sobre o bom e não sobre o analisador ruim, é uma questão errada, mas frequentemente colocada na análise institucional cotidiana e, portanto, muito implicada, às vezes, também na socioanálise. Na origem dessas hesitações e confusões, há talvez um defeito na classificação sumária dos analisadores (portanto, na própria teoria) entre analisadores naturais, analisadores construídos e analisadores históricos.

Todo analisador é um analisador social: desta constatação quase simplista, decorre que a parte do artefato no analisador construído pela socioanálise (o dispositivo) e aquela da espontaneidade no analisador natural são secundárias em relação ao seu caráter de fenômeno social. Este caráter é imediatamente visível pelo analisador histórico, mas, como se trata do produto de uma análise secundária socio-histórica, seu caso retorna àquele de um analisador natural suficientemente espetacular para que os historiadores já o tenham canonizado como um evento ou fenômeno-chave.

Fenômeno social, o analisador não pode jamais ser construído como é, por exemplo, o indicador. Ele não pode ser também mais espontâneo do que um acontecimento estreitamente localizado e incisivo do gênero fait divers ${ }^{9}$. Ele interroga simultaneamente o saber (a palavra, a escrita) e o poder. Mas, em si mesmo, não traz o equivalente da biblioteca de Alexandria ou do Centro de estudos sociológicos, mesmo se estiver fortemente carregado de informação. A natureza dessa informação é que pode nos fazer aproximar o mais possível (fora de uma experiência real) de uma compreensão do analisador social.

Combinadas informação e intervenção, o analisador analisa nosso desejo de saber, tanto quanto nossa posição nas relações sociais. A informação produzida vale, 
antes de tudo, pelas modalidades da produção, isto é, de nosso lugar nas relações sociais quando eu recebo a informação. Um amigo socioanalista, ao retornar de uma intervenção, me diz quase nas primeiras palavras do relatório: "Hoje, eu conheço bem os cinco tipos de escolas de trabalhadores sociais que compõem um IRFETS." E esta informação não tem nada de extraordinária em si mesma. Ela poderia ter sido adquirida há muito tempo, se a necessidade tivesse sido sentida pelos meios livrescos habituais ou por um pedido de informação aos trabalhadores sociais. Mas, é no decorrer de uma intervenção socioanalítica no setor em questão, intervenção que sucede a muitas outras, que este saber aparece como pertinente, como significativo, como digno de ser registrado posteriormente. A situação de interventor externo que era aquela do meu amigo, assim como a frequência das encomendas de intervenção vindas do setor "trabalho social”, produziram a motivação.

Este exemplo banal na psicologia da aprendizagem oferece uma ideia do mecanismo da informação no analisador. Inversamente, como mostra outro exemplo, a ausência de implicação produz diretamente uma informação frágil. Na publicação do meu livro Le gai savoir des sociologues, muitos amigos, ao darem suas contribuições críticas, fizeram-me compreender que eu não tinha ido suficientemente longe no questionamento da política da pesquisa em sociologia. Ora, a organização estatal ou privada da pesquisa é efetivamente o que menos conheço, pelo menos diretamente, porque não participo dos contratos de pesquisa sobre as licitações deste ou daquele ministério, e nunca trabalhei para uma organização ministerial de pesquisa. Por outro lado, alguns dos meus censores poderiam, e desde há muito tempo, ter exercido a crítica ao nível da política de pesquisa, visto que eles participam ou participaram dos contratos do D.G.R.S.T. ou DATAR ${ }^{10}$. Mas, os pesquisadores franceses mais bem informados estão longe de ter a mesma ousadia de seus colegas americanos, a quem se devem revelações da mais alta importância. Estas observações obrigam, consequentemente, a modificar a ideia segundo a qual a ausência de implicação direta produz uma informação frágil. Como é possível constatar, é também, inversamente, uma implicação muito forte que produz, eventualmente, uma fraca informação. Este paradoxo aparente não pode ser explicado senão levando em conta outro aspecto do conceito de analisador, não sua dimensão do saber, mas do poder.

A instituição possui o poder de nos objetivar, de nos coisificar em estatutos e papéis. O analisador "desobjetiva": ele desfaz os estatutos e os papéis, nos restitui a subjetividade. De onde a tendência, por vezes, a privilegiar esta última na pessoa dos 
desviantes, o que é um modo de objetivar os analisadores, de mantê-los à distância quando são exaltados.

A instituição possui o poder de fixar nas normas as relações livres, vivas, interpessoais, tais como se constituem na vida cotidiana mais íntima, como nos movimentos sociais espontâneos: é a institucionalização, negação das forças instituintes e a instauração do positivo, do instituído. O analisador desinstitucionaliza, revela o instituinte sufocado sob o instituído e, ao fazê-lo, perturba o instituído.

A instituição possui o poder de materializar em formas aparentemente neutras e universais, a serviço de todos, forças econômicas e políticas que nos dominam, fingindo nos ajudar e nos defender. O analisador desmaterializa as formas da opressão, revelando as forças que nelas se escondem, e combate quaisquer formas materiais.

Naturalmente, estes três paralelos são bastante abstratos e artificiais: eles se mostram, antes de tudo, didáticos. Para serem verdadeiramente operatórias, estas oposições exigem ser nuançadas e, sobretudo, dialetizadas, porque podem opor uma nova positividade, aquela do analisador, à "má" positividade, aquela da instituição. O que seria uma maneira de deixar escapar a negatividade essencial do analisador, como se vê nas tentativas de contra-instituições que restabelecem, ao final de algum tempo, o aspecto positivo instalado, falsamente universal, da instituição que se acreditava destruir ou pelo menos criticar.

O positivismo, na primeira oposição, traz o risco de subjetivismo e de manipulação. É o risco mais corrente, mas não o mais grave.

$\mathrm{Na}$ segunda oposição, o positivismo consiste em erigir o instituinte como força dominante e destruidora: é o terrorismo, que se vê reinar no início de qualquer empresa anti-institucional, e do qual Hegel tinha mostrado, a propósito da Revolução francesa, a ligação entre o subjetivismo e o idealismo.

O idealismo é precisamente o risco que o positivismo introduz na terceira oposição. A luta contra as formas sociais materializadas, mantidas por forças e sustentando outras forças (um pouco como a parede de uma casa) pode se referir, conscientemente ou não, a uma vontade de transparência ideal, à ideia de forças individuais, ou coletivas, ou metafísicas, que se desenvolvem sem a menor restrição. É o risco mais grave, pois está ligado ao risco de terrorismo, e que se mistura frequentemente com aquele do subjetivismo (cf. o afastamento do subjetivismo de Nietzsche pelo nazismo). 
Dialetizar estas oposições é indispensável: isso significa que é necessário analisá-las sempre no movimento de seu surgimento e de sua evolução; tomar cuidado com a inversão do quantitativo em qualitativo e do qualitativo em quantitativo; e, acima de tudo, descobrir o positivo que se veste de roupagens negativas a fim de recusar qualquer crítica, qualquer transbordamento sobre sua esquerda, qualquer ação dos novos analisadores numa situação nova.

Estas precauções referentes à utilização do conceito de analisador indicam os limites da teoria alternativa com aquela dos indicadores. Lembremos ainda, para memória, a utilização dos dados estatísticos não somente ao nível macrossociológico, mas na abordagem que leva em conta os analisadores.

Resta agora mostrar, ao menos parcialmente, o campo de aplicação da teoria dos analisadores sociais. Para tanto, dois fenômenos muito diferentes, mas situados no domínio da economia, servirão como exemplos: de um lado, o planejamento, de outro, a coletivização. O planejamento, que analisa a crise do Estado, mas com a intenção de tratá-la. A coletivização, visando ir além da crise.

Solange L'Abbate Socióloga, professora associada, aposentada do Departamento de Saúde Coletiva da Faculdade de Ciências Médicas da Universidade Estadual de Campinas / Unicamp. E-mail: slabbate@lexxa.com.br

Yvone Greis Professora de francês prestadora de serviços junto à Faurecia Automobile, Doutora em História e Teoria Literária pelo Instituto de Estudos da Linguagem da Universidade de Campinas/IEL/Unicamp e Doutora em Lettres Modernes pelo Centre d'Études Supérieures de la Renaissance, Universidade François Rabelais de Tours/França.

E-mail: greisyvone@gmail.com

\section{Índice dos autores e personagens citados por René Lourau}

ARMAND, Louis (1727 - 1789) - Francês, dirigente de diversas companhias públicas francesas entre as décadas de 1940 e 1960, dedicou-se a pensar o futuro das empresas no mundo globalizado.

ARTAUD, Antonin (1896 - 1948) - Francês, poeta, ator, escritor, dramaturgo, roteirista e diretor de teatro francês de aspirações anarquistas e fortemente ligado ao surrealismo. 
ATTALI, Jacques (1943) - Argelino, economista, escritor contemporâneo, conselheiro de François Mitterand.

ÁTILA - Rei dos hunos que governou o maior império europeu do ano de 434 a 453.

BARRE, Raymond (1924 - 2007) - Francês, economista, político, primeiro-ministro de 1976 a 1981.

BIDERMAN, Albert D. (1923) - Estadunidense, cientista social, fundou os estudos de indicadores sociais contemporâneos, que apontavam as limitações dos indicadores econômicos.

BOUDON, Raymond (1934 - 2013) - Francês, sociólogo, filósofo, destaque na defesa do liberalismo e do individualismo metodológico e da noção não utilitarista de "racionalidade" na explicação dos fenômenos sociais.

BRECHT, Bertolt (1898 - 1951) - Alemão, dramaturgo, diretor, crítico teatral, escritor de romances, histórias em prosa e poeta.

CHABAN-DELMAS, Jacques (1915 - 2000) - Francês, desportista e político, lutou na resistência francesa, primeiro-ministro de 1969 a 1972.

CORNEILLE, Pierre (1606 - 1684) - Francês, escritor, poeta, tradutor e dramaturgo do século XVII.

CROZIER, Michel (1922 - 2013) - Francês, sociólogo, especialista no estudo das organizações.

DE GAULLE, Charles (1890 - 1970) - Francês, oficial do exército, estadista. Presidiu o governo provisório da República Francesa de 1944 a 1946. Presidente da França em 1958, reeleito em 1965 até sua renúncia em 1969.

DELORS, Jacques Lucien Jean (1925) - Francês, político, presidente da Comissão Europeia de 1985 a 1995.

FRIEDMAN, Milton (1912 - 2006) - Estadunidense, economista, fundador da Escola de Chicago, vencedor do Prêmio Nobel de Economia em 1976, expoente do pensamento neoliberal.

GORHAM, William (1930) - Estadunidense, economista, presidente fundador do Urban Institute, que realiza pesquisas de políticas econômicas e sociais.

GROSS, David (1941) - Estadunidense, teórico e físico.

GUÉNON, René-Jean-Marie-Joseph (1886 - 1951) - Francês, cujo nome muçulmano era Shaykh 'Abd al-Wâhid Yahyâ, foi intelectual esotérico e, embora de forma controversa, influenciou escritores e políticos da extrema direita de várias partes do mundo. 
HEGEL, Georg Wilhelm Friedrich (1770 - 1831) - Alemão, um dos filósofos mais influente no pensamento ocidental.

LENIN, Vladimir (1870 - 1924) - Russo, comunista, político, revolucionário, ideólogo marxista, líder do governo soviético de 1917 a 1922.

MARX, Karl (1818 - 1883) - Alemão, filósofo, historiador, economista e revolucionário.

MASSÉ, Pierre (1989 - 1987) - Francês, economista, comissário geral do governo de Charles de Gaulle entre 1959 e 1966.

MENDÈS-FRANCE, Pierre (1907 - 1982) - Francês, político, socialista, primeiroministro francês entre 1954 e 1955.

MONNET, Jean (1888 - 1979) - Francês, político, atuou nos bastidores de governos europeus e estadunidenses como um internacionalista pragmático.

NIETZSCHE, Friedrich Wilhelm (1844 - 1900) - Alemão, filósofo, filólogo, crítico cultural, compositor e poeta.

POMPIDOU, Georges Jean Raymond (1911 - 1974) - Francês, político, primeiroministro da França de 1962 a 1968 e presidente de 1969 até sua morte.

RATHENAU, Walther (1867 - 1922) - Alemão, industrial, político, escritor, ministro de Relações Exteriores.

ROCARD, Michel (1930 - 2016) - Francês, político, socialista, primeiro-ministro de 1988 a 1991, deputado no parlamento europeu de 1994 a 2009.

SALAZAR, Antônio de Oliveira (1889 - 1970) - Português, advogado, presidente do Conselho de Ministro de Portugal e depois ditador de 1933 a 1968.

SARTRE, Jean-Paul Charles Aymard (1904 - 1980) - Francês, filósofo existencialista, escritor e crítico francês, defensor da participação ativa dos intelectuais na vida política e social.

SPEER, Albert (1905 - 1981) - Alemão, arquiteto, nazista, escreveu diário que autobiografa seu relacionamento próximo com Hitler.

STALIN, Josef (1978 - 1953) - Georgiano, comunista, político, líder do governo soviético entre 1922 e 1953.

TURGOT, Anne Robert Jacques (1727 - 1781) - Francês, economista e estadista.

VERNE, Júlio (1828 - 1905) - Francês, escritor destacado, no gênero da fícção cientifica, pela riqueza de detalhes. 


\footnotetext{
${ }^{1}$ Novo acordo foi um conjunto de medidas criado no governo de Franklin Delano Roosevelt (1933-1945), nos Estados Unidos, durante a crise do liberalismo econômico em 1929.

${ }^{2}$ Instituto Nacional de Estatística e Estudos Econômicos.

3 Personagem "mudo" de uma tira de quadrinhos francesa em quatro imagens. Ele foi criado e desenhado por André Daix, em 1934. Representa o cientista louco, distraído ou desastrado.
}

${ }^{4}$ Denominação da Comissão de Planejamento do Estado soviético que se encarregou de dividir a recémcriada república socialista em 'unidades funcionais'.

${ }^{5}$ Massachusetts Institute of Technology; Institut de technologie du Massachusetts; ou ainda, Instituto de tecnologia de Massachuttes.

${ }^{6}$ Jogo de palavras em francês: mépris (desprezo), mé-prix (des-preço, desapreço).

${ }^{7}$ Família de origem suíça que reinou durante 645 anos sobre vários povos da Europa Central, cuja dinastia ocupou o trono austríaco até o fim da Primeira Guerra Mundial e dominou territórios que se estendiam de Gibraltar à Hungria e da Sicília a Amsterdã.

${ }^{8}$ A questão da natureza do ator remete, em última instância, ao problema metafísico do ator da natureza, deus, maná, energia etc. Evidentemente, não é indiferente se o ator é um especialista (ou um grupo de especialistas), um louco, uma criança, um homem, uma mulher, um desviante, um Branco, um Negro, um Amarelo, um Vermelho, um mestiço, um velho, um jovem, um animal mamífero ou não, vertebrado ou não, ou ainda um destes aparelhos que na física se denomina precisamente como analisadores (desde os instrumentos de medida mais comuns: termômetro, barômetro, analisador de poluição etc, até os mais sofisticados). Ao se referir à teoria dos analisadores, é claro que o "ator" é não somente um organismo capaz de absorver e de restituir uma informação ("revelador"), mas ainda um elemento interventor, agindo sobre a situação que atua sobre ele (donde a impossibilidade de se contentar com a metáfora de catalisador). $\mathrm{O}$ que exclui do papel do ator qualquer órgão vivo ou artificial que não cumpre ou que nada prova até que preencha estas duas condições.

A propósito da expressão "papel do ator", lembremos que na tradição teatral o personagem do Ator, sobretudo frequente na produção elisabetana, funciona como analisador da instituição teatral bem antes que Brecht e seus discípulos introduzissem na representação um dispositivo analisador, ele mesmo bem superior às tentativas do teatro naturalista: o distanciamento no jogo, a abertura sobre os bastidores e a eliminação da cortina de palco, ao mesmo tempo que da cortina de fundo, em Brecht, depois o teatro em círculo ou o teatro na sala ou ainda a cena de campo expandido de Artaud, etc, continuam por diversos meios mais ou menos analisadores da morte da ilusão teatral. Morte sem cessar protelada pelo estetização de todos os meios anti-institucionais e insuficientemente analisadores da "ilusão cômica" (Corneille), isto é, da instituição teatral como lugar da representação, sublimação da ação julgada impossível. (Esta é a única nota que consta no texto original).

9 Expressão francesa que aborda episódio do cotidiano, frequentemente dramático, podendo tender à banalização. Crônica do cotidiano seria a tradução mais aproximada.

${ }^{10}$ Délégation Générale à la Recherche Scientifique et Technique (Delegação Geral da Pesquisa Científica e Técnica) / Délégation interministérielle à l'aménagement du territoire et à l'attractivité régionale (Aproximadamente: Delegação interministerial para o agenciamento territorial e atratividade regional). 